\title{
EFFECTS OF SOLAR RADIATION ON THE FORMATION OF WEAK WET SNOW
}

\author{
by
}

Kaoru Izumi

(Research Institute for Hazards in Snowy Areas, Niigata University, Niigata 950-21, Japan)

\section{ABSTRACT}

Laboratory and field experiments on hardness of snow have shown that the free water contained in snow decreases its hardness, and that solar radiation further decreases hardness down to a value below the limit of that which would result only from the influence of the water content of snow. A quantitative relationship between the amount of solar radiation absorbed by snow and decrease in snow hardness was derived. Thin-section analyses of snow were used to reveal the mechanism of decrease in snow hardness which had been caused by solar radiation.

\section{INTRODUCTION}

In the Hokuriku District of Japan, and especially in Niigata Prefecture, a tremendous amount of snow accumulates in winter. The distinctive feature of this snow is that it frequently contains liquid water even in mid-winter. In the Prefecture we have had a number of avalanche accidents which have been caused by a sliding plane of wet snow; some of them, such as the Ohkura avalanche in 1981 and the Maseguchi avalanche in 1986, were large-scale surface avalanches of thick dry snow occurring during heavy snowfall and resulting in severe disaster. By pit observations in situ and by meteorological analysis, it has been deduced that a thin layer of weak wet snow several centimeters thick, which provided the sliding plane for these surface avalanches, was formed by the effects of solar radiation at the snow surface and was then buried deep in the snow cover by subsequent heavy snowfall before the avalanche was released (Izumi, 1987).

In this present study, the definition of hardness suggested by Kinosita (1960) has been used as an indicator of the mechanical strength of snow samples. Decrease in the hardness of snow due to its immersion in water at $0^{\circ} \mathrm{C}$ or to the effects of solar radiation have been studied both in a cold room and in the field. DECREASE IN HARDNESS OF SNOW DUE TO
IMMERSION IN WATER AT $0{ }^{\circ} \mathrm{C}$

Izumi and Akitaya (1985) have reported that for a given dry density the hardness of wet snow decreases exponentially with an increase in its free water content. Because of this relationship, the hardness of wet snow is considered to have a minimum value when the snow is completely saturated with water, that is when the pore spaces in the snow are completely filled with water. Hence, the changes in hardness of natural snow were measured by immersing snow specimens of an ambient temperature in water at $0^{\circ} \mathrm{C}$ in a cold laboratory at $1^{\circ} \pm 1^{\circ} \mathrm{C}$. Hardness, $R$, of the immersed snow was found to decrease rapidly and then to reach an almost constant value within a total period of $3 \mathrm{~h}$. This constant value of hardness was termed the water saturation hardness, $R_{\mathrm{S}}$. The tendency to undergo changes in hardness was noted in all of the 122 snow specimens studied, and was apparently independent of both snow type and of water content before immersion. The

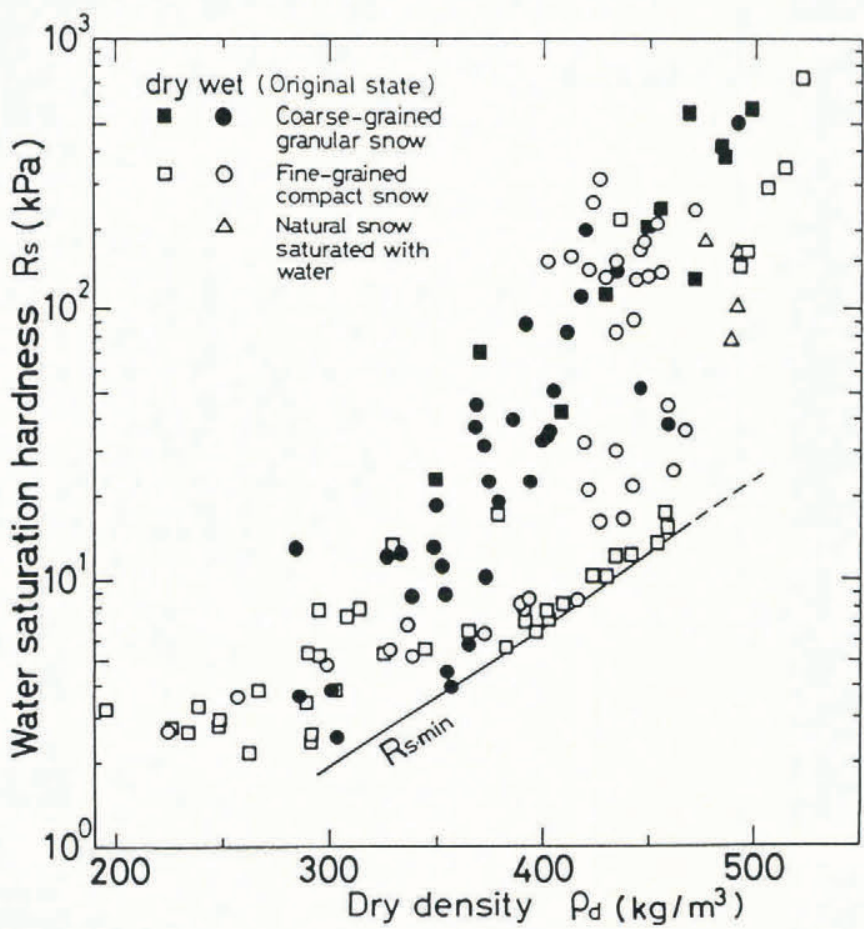

Fig. 1. Relationship between water saturation hardness, $R_{\mathrm{S}}$, and original dry density, $\rho_{\mathrm{d}} \cdot R_{\mathrm{S}-\min }$ indicates the lower limit of $R_{\mathrm{S}}$ values.

relationship between water saturation hardness, $R_{\mathrm{S}}$, and dry density, $\rho_{\mathrm{d}}$, of the original snow specimens is shown in Figure 1. The lower limit of $R_{\mathrm{S}}$ is clearly shown by the line labelled $R_{\mathrm{S}-\min }$. The value of $R_{\mathrm{S} \text {-min }}$ increases with an increase in dry density, indicating the minimum hardness of snow due to its water content alone.

If decrease in the hardness of wet snow were caused only by the effects of its water content, then the hardness of unsaturated snow should be at least slightly greater than the $R_{\mathrm{S}-\mathrm{min}}$ value for its corresponding dry density. However, in the field, Izumi (1987) occasionally observed unsaturated wet snow with a lower hardness than the $R_{\mathrm{S} \text {-min }}$ at surface snow layers which were thought to have been exposed to active solar radiation. Wakahama (1975) observed that the hardness of snow at the surface layer decreased by two orders of magnitude during the daytime in the snow-melt season due to strong solar radiation effects. Consequently, it is now considered that decrease in the hardness of wet snow to a value below $R_{\mathrm{S}-\min }$ is caused by solar radiation.

DECREASE IN HARDNESS OF SNOW DUE TO SOLAR RADIATION

In order to study the mechanism of this decrease in 


\section{Light $(250 \mathrm{~W}, 5500 \mathrm{~K}) \times 4$}
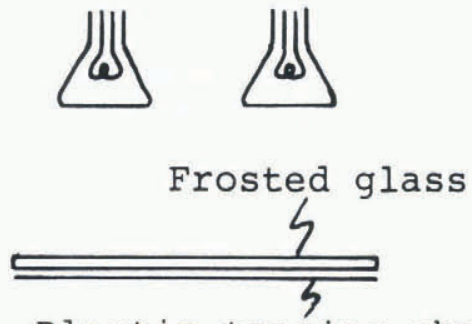

Plastic tracing sheet

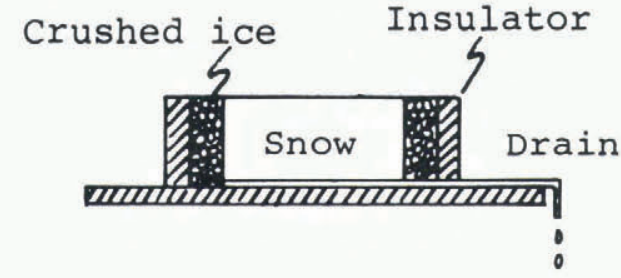

\section{[ Cold room temperature: $1 \pm 1^{\circ} \mathrm{C}$ ]}

Fig. 2. Apparatus for laboratory experiments.

snow hardness, experiments were carried out both in a laboratory and in the field.

\section{Laboratory experiments}

Snow blocks with uniform texture were cut out from deep layers of natural snow cover in places where it was considered reasonable to assume that solar radiation had scarcely influenced snow texture. Two snow-block samples of the same dimensions $200 \mathrm{~mm} \times 200 \mathrm{~mm}$ in horizontal size between 60 and $170 \mathrm{~mm}$ in thickness were prepared at a time from a snow block. One specimen was set in a container whose sides and bottom were insulated, in a cold laboratory with an ambient temperature of $1^{\circ} \pm 1^{3} \mathrm{C}$ (Fig. 2). Artificial solar radiation was provided from a light source composed of four $250 \mathrm{~W}$ color-photography flood lamps by scattering the light with a combination of a frosted glass plate and a plastic tracing sheet. This artificial solar radiation, which had almost the same spectral characteristics of natural solar radiation, was applied constantly to the specimen for $130-450 \mathrm{~min}$ in the cold laboratory and its effect on snow hardness and snow texture was studied. This is referred to as experimental condition A (radiation) and the hardness of the snow sample produced as the result of these conditions is called $R_{\mathrm{A}}$. The intensity of the artificial solar radiation at the surface of the specimen before and after each experiment was measured with a pyranometer and was found to range from $0.3-0.4 \mathrm{~kW} / \mathrm{m}^{2}$. Such a range of mid-day values is often observed on fine days in the months of December and January in Niigata Prefecture. A second snow specimen was set in a specimen container similar to that used for the first in a laboratory with an ambient temperature of $24-25^{\circ} \mathrm{C}$ and kept away from solar radiation so as to provide a comparison with the specimen kept under artificial solar radiation. This experimental condition is referred to as B (non-radiation), and the snow hardness is called $R_{\mathrm{B}}$. As snow melting proceeded with time at the upper surface, an observation layer $30 \mathrm{~mm}$ thick was selected at a particular level within the specimen, and the experiment was continued until the upper surface of the observation layer became the snow surface.

Typical results of the comparative experiment on decrease in hardness of snow under/without solar radiation are shown in Figure 3. The observation layer was selected between the levels of 3 and $6 \mathrm{~cm}$ from the bottom of the specimen. For this experiment, wet fine-grained compact snow of $\rho_{\mathrm{d}}=396 \mathrm{~kg} / \mathrm{m}^{3}, W=2.2 \%$ and $R=99.0 \mathrm{kPa}$ was used. The amount of artificial solar radiation applied to the surface of the specimen under condition A was $5.9 \mathrm{MJ} / \mathrm{m}^{2}$ over $280 \mathrm{~min}$. The surface level of each snow block specimen decreased in a similar manner from $100 \mathrm{~mm}$ down

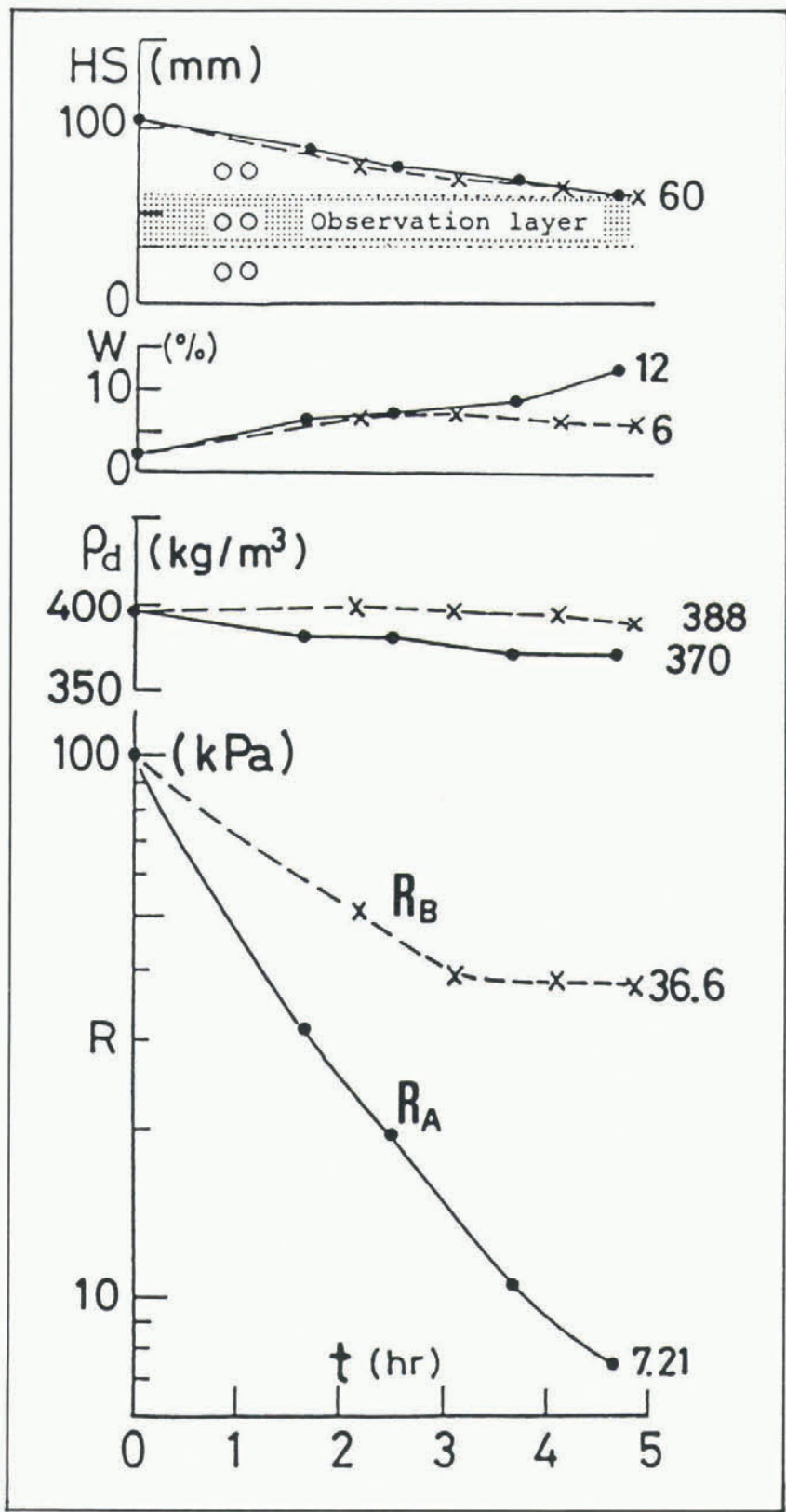

Fig. 3. Decrease in hardness, $R$, of snow at $0^{\circ} \mathrm{C}$. Solid line: under solar radiation; dashed line: without solar radiation. HS: surface level of snow specimen; $W$ : water content; $\rho_{\mathrm{d}}$ : dry density of snow.

to $60 \mathrm{~mm}$ during the time of the experiment. The changes with time in the free-water content, $W$, and the dry density, $\rho_{\mathrm{d}}$, of the observation layer under condition $\mathrm{A}$ (radiation) showed fairly close agreement with changes observed under condition $\mathrm{B}$ (non-radiation). On the other hand, the hardness values $R_{\mathrm{A}}$ and $R_{\mathrm{B}}$ showed remarkable differences. Under condition $B$, the hardness of the observation layer decreased with time for the first $3 \mathrm{~h}$ of the experiment and then attained a constant value, while under condition A snow hardness decreased more quickly and continuously until the end of the experiment, finally reaching a value of approximately $20 \%$ of that of $R_{\mathrm{B}}$. Consequently, it was presumed that this extraordinarily large decrease in the hardness of snow under condition A (radiation), which could not be explained solely by changes in water content and dry density, was caused principally by the artificial solar radiation. All other comparative experiments using a procedure like this showed a similar trend to Figure 3, with $R_{\mathrm{A}}$ finally reaching a value of between 80 and $10 \%$ of $R_{\mathrm{B}}$. The difference in the percentage depended on the properties of the original snow and the amount of solar radiation applied. 


\section{Mechanism of decrease in snow hardness}

To clarify the mechanism of decrease in hardness of snow observed in these experiments, thin-section analyses were performed before and after the comparative experiments. Vertical thin sections of the observation layer prepared by the aniline method (Kinosita and Wakahama, 1959) were photographed under a microscope using polarized light. Before preparing the thin sections, most of the free water in the specimen was removed with tissue paper. In this way it is possible to reduce the free-water content of wet snow to only a few per cent of its total mass (Wakahama, 1965). Using the photographs of the sections, measurements were made of the grain area and the bond area of the snow with an image analyzer. Grain area was defined by the cross-sectional area of a snow grain which appeared on the surface of the thin section, and bond area by the cross-sectional area of an inter-grain ice bond on the assumption that the cross-section of an ice bond had a circular shape with a diameter equal to the neck width which appeared on the photograph. From the grain area distributions of the observation layer in the initial and final stages under experimental conditions $\mathrm{A}$ and $\mathrm{B}$, it could generally be said that small grains (snow grains with a small grain area) decreased in number while large grains became more numerous. Moreover, larger grains than the largest ones of the initial stage were newly created through snow-melting processes under both sets of experimental conditions. Such a change in grain-size distribution was assumed to have been caused by grain coarsening in snow whose water content increased. In fact, after the experiment shown in Figure 3, mean grain area had increased by about $40 \%$ and the number of snow grains per unit area had decreased by about $20 \%$, regardless of which condition, A or B, had been applied. Wakahama (1965) observed similar increases in grain-size in wet snow with a $3-5 \%$ water content. Meanwhile, total bond area per unit volume of the observation layer decreased more under condition $A$ than under condition B. Figure 4 shows the relationship between total bond area and hardness of the observation layer in the experiment of Figure 3. It indicates that the logarithm of snow hardness is proportional to the total bond area in unit volume of snow, and shows that this total bond area depends mainly on the number of inter-grain ice bonds.

From the results of the thin-section analyses described above, the following mechanism for snow weakening by melting is proposed. The sensible and latent heat transferred to the snow surface causes snow melting at the snow surface even without solar radiation, and the melt water then infiltrates the snow. Snow which has increased its

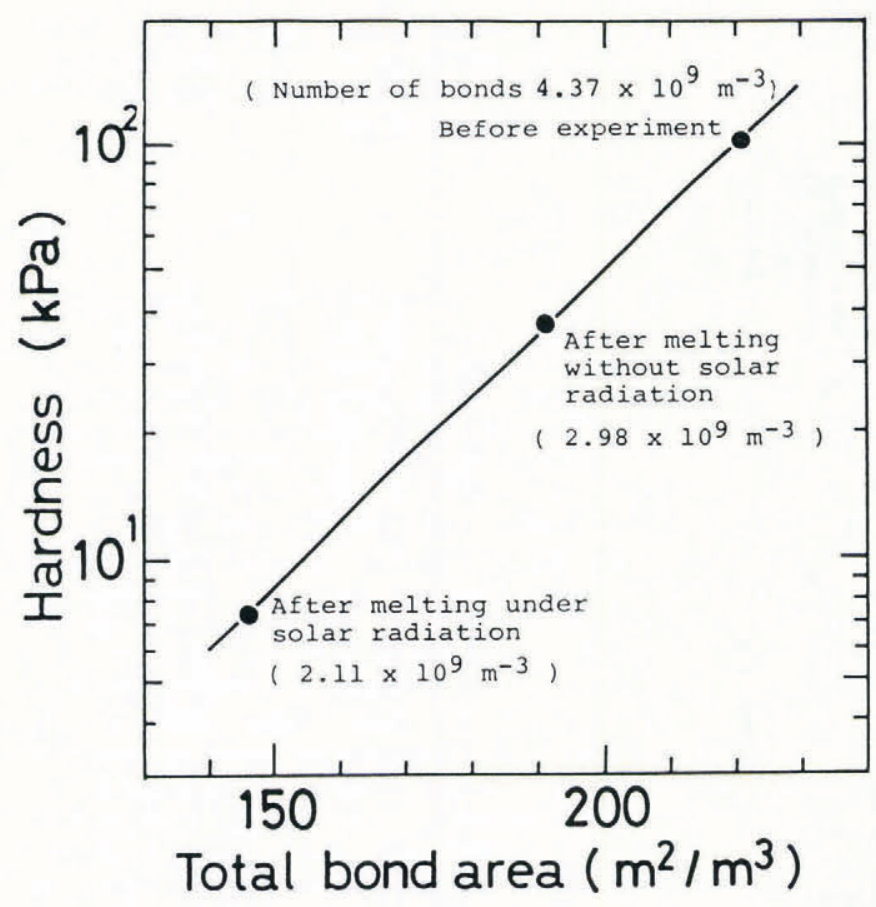

Fig. 4. Hardness and total bond area of the observation layer shown in Figure 3. water content by melting decreases its hardness by the grain-coarsening process, lessening the number of inter-grain ice bonds in unit volume with a decrease in the number of snow grains as a result of the increase in grain-size. The amount of decrease in snow hardness depends on the amount of increase in water content. The maximum decrease in hardness will appear when the snow is saturated with water, that is on reaching $R_{\mathrm{s}}$.

Solar radiation penetrating into the snow cover is absorbed partially by snow grains, resulting in snow melt even inside the snow cover and also in increase of water content. Because solar radiation is predominantly absorbed at grain boundaries, and because grain boundaries very frequently exist at inter-grain ice bonds, bonds are easily weakened or broken by solar radiation. The number of inter-grain ice bonds decreases due both to such internal melting at the grain boundary and to the grain-coarsening process. Consequently, hardness of snow greatly decreases due to the effects of solar radiation.

\section{Decrease in hardness of snow to a value below $\boldsymbol{R}_{\mathrm{s}-\mathrm{min}}$}

Field experiments on changes in hardness of snow at $0^{\circ} \mathrm{C}$ under natural solar radiation were carried out using a similar procedure to that of the laboratory experiment in the months of March and April 1986. The snow-block specimen taken out from the deep layers of the snow cover was set tightly in a hole excavated in the surface of the snow cover so that its upper surface was at the same level as that of the snow cover, and exposed to solar radiation during the daytime. Incoming solar radiation was measured by a pyranometer at the experimental site, and it was found that the amount of solar radiation applied to the snow surface during any experiment ranged from 6.7 to $15.6 \mathrm{MJ} / \mathrm{m}^{2}$. A considerable number of the field experiments showed hardness decreases to below $R_{\mathrm{S}-\mathrm{min}}$. Whether hardness decreases to below $R_{\mathrm{S}-\mathrm{min}}$ or not depends on the amount of solar radiation applied and also on the properties of snow specimen. It has been proved that under natural solar radiation snow hardness can decrease to a value below $R_{\mathrm{S}-\min }$, which is the minimum hardness possible as a result of the effect of water content of snow alone.

Relationship between amount of solar radiation absorbed by snow and decrease in its hardness

A high proportion of incoming solar radiation is reflected by snow at its surface according to its albedo. The remainder is subject to absorption and scattering, so that its intensity is reduced gradually with depth. It is usually assumed for the sake of simplicity that a snow mass acts as an homogeneous diffusing medium for radiation, and that therefore solar radiation is attenuated according to the Bouger-Lambert law. Consequently, the amount of solar radiation, $Q$, absorbed by unit area of snow layer of depth $z_{1}$ to $z_{2}$ in time $t_{1}$ to $t_{2}$ calculated by Equation (1)

$$
Q=\int_{t_{1}}^{t_{2}} \int_{z_{1}}^{z_{2}} \mu\left(1-\alpha I_{0} \exp (-\mu z) \mathrm{d} z \mathrm{~d} t\right.
$$

where $\alpha, \mu$, and $I_{0}$ are respectively albedo, extinction coefficient, and intensity of incoming solar radiation at the snow surface. The thickness of an observation layer, $z_{2}-z_{1}$, was selected as $30 \mathrm{~mm}$, because this was the sampling thickness necessary for our measurements of the density and water content of snow, and also because the depth affected by the penetration of the gauge to measure snow hardness by the Kinosita method was kept from exceeding $30 \mathrm{~mm}$. Accordingly, a calculation of $Q$ was made for a $30 \mathrm{~mm}$ thick observation layer. The values of albedo and extinction coefficient of snow obtained by Kojima (1979) and Fukami and Kojima (1980) were used in our analysis.

To eliminate the effect of changes in dry density and water content, and clarify the effect of solar radiation on snow hardness, the hardness ratio, $\gamma$, was defined as,

$$
\gamma=R_{1} / R_{2}
$$

where $R_{1}$ is final hardness of an observation layer under 


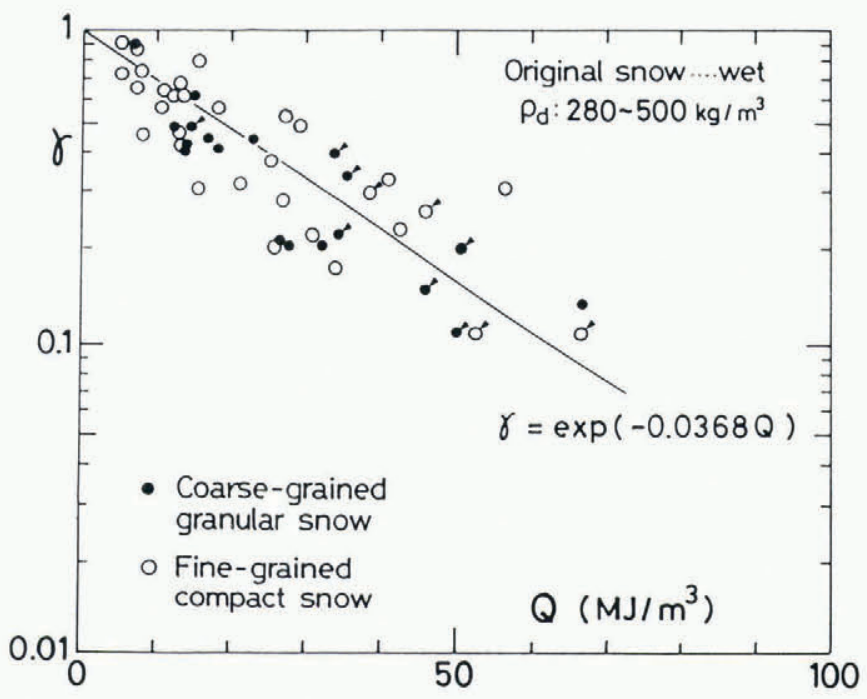

Fig. 5. Relationship between absorbed solar radiation, $Q$, and hardness ratio, $\gamma$. Circles with arrow: field experiments; circles without arrow: laboratory experiments.

solar radiation during an experiment, and $R_{2}$ is final hardness of the layer when its initial dry density and water content change without solar radiation to the same values as those measured after a radiation experiment. $R_{2}$ is calculated using the relationship between hardness, dry density, and water content of wet snow obtained by Izumi and Akitaya (1985), and with these values $\gamma$ represents the rate of hardness decrease resulting from solar radiation alone. Figure 5 shows the relation between the amount of solar radiation, $Q$, absorbed by wet snow and the hardness ratio, $\gamma$, obtained from laboratory and field experiments. The hardness ratio decreases exponentially with an increase in $Q$ independently of snow type both in the laboratory and in the field. The relationship obtained in the laboratory is identical with that obtained in the field, and this finding confirms that the artificial solar radiation used in the laboratory had almost the same influence on snow hardness as natural solar radiation. Assuming that $y=1$ when
$Q=0$, the regression equation for all data shown in Figure 5 is

$$
\gamma=\exp (-0.0368 Q)
$$

As mentioned earlier, in the Hokuriku District of Japan wet-snow layers exposed to solar radiation at the snow surface and weakened by it may later be buried under a depth of snow cover by a subsequent heavy snowfall, and thick new snow falling on the weak layer may become unstable enough to be released as a surface avalanche. Using Equation (3), the rate of hardness decrease of the weak layer can be calculated from the amount of solar radiation absorbed, and in this way potential avalanche danger can be estimated from the snowfall data.

\section{ACKNOWLEDGEMENT}

The author thanks Professor H. Shimizu of the Institute of Low Temperature Science for his helpful suggestions, and also E. Hestnes of the Norwegian Geotechnical Institute for his valuable comments.

\section{REFERENCES}

Fukami, H. and K. Kojima. 1980. Extinction measurements of solar radiation within a snow cover. [In Japanese.] Low Temp. Sci., Ser. A, 39, 119-126.

Izumi, K. 1987. Studies on the hardness of wet snow and its decrease due to solar radiation. Niigata, Niigata University. Research Institute for Hazards in Snowy Areas, 1-42. (Annual Report 9.)

Izumi, K. and E. Akitaya. 1985. Hardness of wet snow. Ann. Glaciol., 6, 267-268.

Kinosita, S. 1960. The hardness of snow. I. [In Japanese.] Low Temp. Sci., Ser. A, 19, 119-134.

Kinosita, S. and G. Wakahama. 1959. Thin sections of deposited snow made by the use of aniline. [In Japanese.] Low. Temp. Sci.. Ser. A, 18, 77-96.

Kojima, K. 1979. Mechanism of snow melting and heat balance. [In Japanese.] Meteorological Society of Japan. Note on Meteorological Study 136.

Wakahama, G. 1965. Metamorphisms of wet snow. [In Japanese.] Low Temp. Sci., Ser. A, 23, 51-66.

Wakahama, G. 1975. The role of meltwater in densification processes of snow and firn. International Association of Hydrological Sciences Publication 114 (Symposium at Grindelwald - Snow Mechanics), 66-72. 